\title{
Increased Risk of Herpes Zoster in Young and Metabolically Healthy Patients with Inflammatory Bowel Disease: A Nationwide Population-Based Study
}

\author{
Hosim Soh ${ }^{1}$, Jaeyoung Chun ${ }^{1}$, Kyungdo Han ${ }^{2}$, Seona Park ${ }^{1}$, Gukhwan Choi ${ }^{1}$, Jihye Kim ${ }^{1,3}$, Jooyoung Lee ${ }^{4}$, Jong Pil Im ${ }^{1}$, and \\ Joo Sung $\mathrm{Kim}^{1}$ \\ ${ }^{1}$ Department of Internal Medicine and Liver Research Institute, Seoul National University College of Medicine, ${ }^{2}$ Department of Medical \\ Statistics, College of Medicine, The Catholic University of Korea, ${ }^{3}$ Department of Internal Medicine, CHA Gangnam Medical Center, CHA \\ University School of Medicine, and ${ }^{4}$ Department of Internal Medicine and Healthcare Research Institute, Healthcare System Gangnam Center, \\ Seoul National University Hospital, Seoul, Korea
}

Background/Aims: The risk of herpes zoster ( $\mathrm{HZ}$ ) among patients with inflammatory bowel disease (IBD) remains unclear in terms of age and metabolic comorbidities, including diabetes mellitus, hypertension, or dyslipidemia. We conducted a nationwide population-based study to investigate the risk of $\mathrm{HZ}$ in patients with IBD. Methods: From 2010 to 2013, a retrospective study was performed using claims data in Korea. We compared the incidence of $\mathrm{HZ}$ between 30,100 IBD patients (10,517 Crohn's disease [CD] and 19,583 ulcerative colitis [UC] patients) and 150,500 non-IBD controls matched by age and sex. Results: During a mean follow-up of 5.0 years, incidence rates of $\mathrm{HZ}$ (per 1,000 person-years) were 13.60, 14.99, and 9.19 in the CD, UC, and control groups, respectively. The risk of $\mathrm{HZ}$ was significantly higher in patients with $C D$ (adjusted hazard ratio [HR], 2.13; $p<0.001$ ) and UC (adjusted HR, 1.40; $p<0.001$ ) than in the controls. The impact of $\mathrm{CD}$ on developing $\mathrm{HZ}$ was significantly more prominent in younger patients (adjusted HR, 2.61 for age $<15$, whereas 1.39 for age $\geq 60$; interaction $p=0.001$ ) and in patients without metabolic comorbidities (adjusted HR, 2.24, whereas 1.59 in those with metabolic comorbidities; interaction $\mathrm{p}=0.015)$. Moreover, the impact of $\mathrm{UC}$ on developing $\mathrm{HZ}$ significantly increased in younger patients (adjusted HR, 2.51 in age $<15$, whereas 1.22 in age $\geq 60$; interaction $p=0.014$ ) and patients without metabolic comorbidities (adjusted HR, 1.49 whereas 1.16 in those with metabolic comorbidities; interaction $\mathrm{p}<0.001)$. Conclusions: IBD was associated with an increased risk of $\mathrm{HZ}$, especially in younger patients without metabolic comorbidities. (Gut Liver 2019;13:333-341)
Key Words: Claims data; Herpes zoster; Inflammatory bowel disease

\section{INTRODUCTION}

Herpes zoster (HZ), also known as shingles, is caused by the reactivation of the latent varicella-zoster virus (VZV), which resides in the sensory ganglia and dorsal nerve roots after varicella infection. The disease manifests as painful vesicular eruptions usually limited to one to three dermatomes, and neurological complications may persist for months or years, resulting in functional debilitation and poor quality of life. ${ }^{1-3}$ Previous studies indicated an incidence of HZ of 1.2 to 4.9 cases per 1,000 person-years worldwide, ${ }^{4,5}$ while a recent populationbased study in Korea reported an HZ incidence of 10.4 per 1,000 person-years in the general population, ${ }^{6}$ indicating an incidence relatively higher than that observed in other countries.

Risk factors for HZ include old age, cancer, immune-compromised conditions such as organ transplantation or human immunodeficiency virus infection, and metabolic comorbidities including hypertension, dyslipidemia, and diabetes mellitus (DM). ${ }^{7-10}$ Inflammatory bowel disease (IBD), including Crohn's disease (CD) and ulcerative colitis (UC), is also known as a risk factor for HZ. To date, epidemiological data have shown that in Western countries, the risk of $\mathrm{HZ}$ is higher patients with IBD than in the general population. Data from the General Practice Research Database in the United Kingdom showed that the incidence of $\mathrm{HZ}$ was higher in patients with $\mathrm{CD}$ and UC than in

Correspondence to: Joo Sung Kim (https://orcid.org/0000-0001-6835-4735)

Department of Internal Medicine and Liver Research Institute, Seoul National University College of Medicine, 103 Daehak-ro, Jongno-gu, Seoul 03080, Korea

Tel: +82-2-740-8112, Fax: +82-2-743-6701, E-mail: jooskim@snu.ac.kr

Received on July 3, 2018. Revised on October 8, 2018. Accepted on October 11, 2018. Published online March 15, 2019 pISSN 1976-2283 eISSN 2005-1212 https://doi.org/10.5009/gnl18304

@ This is an Open Access article distributed under the terms of the Creative Commons Attribution Non-Commercial License (http://creativecommons.org/licenses/by-nc/4.0) which permits unrestricted non-commercial use, distribution, and reproduction in any medium, provided the original work is properly cited. 
non-IBD controls (incidence rate ratio [IRR], 1.6 in CD and 1.2 in UC). ${ }^{2,11}$ A retrospective cohort analysis of insurance data collected in the United States demonstrated an IRR of 1.8 for $\mathrm{HZ}$ in $\mathrm{CD}$ patients versus those in the general population. ${ }^{12}$ However, the incidence of $\mathrm{HZ}$ among Asian patients with IBD remains unclear. Moreover, whether the risk of $\mathrm{HZ}$ varies among patients with IBD according to the presence of known HZ risk factors, such as age and metabolic comorbidities, has not yet been evaluated. The aim of this nationwide population-based study was to determine the incidence and risk of $\mathrm{HZ}$ in Asian patients with IBD, especially in terms of age and metabolic comorbidities.

\section{MATERIALS AND METHODS}

\section{Data source}

The Korean government runs a National Health Insurance (NHI) service wherein all health care use information is compiled as part of a comprehensive database that enrolls almost all citizens in Korea (approximately 51 million individuals). ${ }^{13}$ Within this system, the NHI service has established a registration program for rare intractable diseases (RIDs) for a copayment reduction system. To be registered in the RID program, specific diagnostic criteria must be fulfilled and physician-certified. ${ }^{14}$ Thus, the RID program in the NHI database allows us to calculate events that occur in unselected patient populations in Korea so that the whole spectrum and severity of the disease extent in the country is represented.

This study used data from the NHI, from which data related to patient demographics and medical treatment claims for inpatient and outpatient care, including diagnoses, prescriptions, and procedures, can be obtained. Diagnosis statements were defined by the International Classification of Diseases, 10th revision (ICD-10) and the RID database of the NHI.

\section{Patient identification}

Patients with IBD and no history of HZ during a washout period from January 2005 to December 2009 were identified, and their data were extracted from the NHI database from January 2010 to December 2013 to create the IBD cohort. To identify patients with IBD, ICD-10 codes and the RID database were utilized. Patients with $\mathrm{CD}$ were defined as patients with both the ICD-10 code K50 and the RID code V130, while patients with UC were defined as those with both the ICD-10 code K51 and the RID code V131. Patients newly diagnosed with IBD between 2010 and 2013 were defined as the "incident" group, whereas patients previously diagnosed with IBD and coded accordingly from January 2010 to December 2013 were defined as the "prevalent" group. Patients who were diagnosed with IBD before January 2010 but not coded between January 2010 and December 2013 were removed from the NHI database dataset. Thus, 30,100 IBD patients (10,517 CD patients and 19,583 UC patients) were identified from the NHI database. To validate the authenticity of patient selection via ICD-10 and RID codes, we retrospectively reviewed medical charts at Seoul National University Hospital, a tertiary referral hospital in Korea. Patients diagnosed with IBD by both ICD-10 and RID codes between January 2010 and December 2013 were identified, and their medical records were reviewed to evaluate the accuracy of the diagnoses. The sensitivities of a diagnosis of CD or UC obtained using ICD10 and RID codes were 94.5\% (312/330) and 96.4\% (482/500), respectively. In the non-IBD control cohort, 150,500 age- and sex-matched controls were randomly selected from non-IBD individuals at a 5:1 ratio. Randomization was performed using an algorithm within the SAS program (SAS Institute Inc., Cary, NC, USA).

\section{Endpoint}

The primary endpoint was newly diagnosed HZ, which was defined as a diagnosis with an ICD-10 code for HZ (B02) with either a prescription for an oral antiviral medication for at least 5 days or the prescription of more than one antiviral injection administered between 2010 and 2015. Patients without HZ during the follow-up period were censored at the date of dropout (due to death or emigration) or at the end of follow-up, whichever came first.

\section{Covariates}

The ICD-10 codes used for the identification of covariates in this study included DM (E11-14), hypertension (I10-13, I15), dyslipidemia (E78), cancer (C00-96), patient income, and living area (rural vs urban). Metabolic comorbidities were defined as the presence of at least one of the followings: DM, hypertension, or dyslipidemia. Information on the medication(s) used for IBD, which include steroids; immunomodulators, including azathioprine, 6-mercaptopurine, and methotrexate; and antitumor necrosis factor (anti-TNF) agents, including infliximab and adalimumab, were also collected.

\section{Statistical analysis}

Continuous variables are presented as the means \pm standard deviations, and categorical variables are presented as numbers and percentages. To compare characteristics between cohorts, the Student t-test was used for continuous variables, and the chi-square test was used for binary and categorical variables. The incidence rates of $\mathrm{HZ}$ were calculated per 1,000 personyears. Multivariate Cox regression models were used to assess the risk of new-onset $\mathrm{HZ}$ associated with baseline characteristics. The cumulative incidence of $\mathrm{HZ}$ for each group was plotted with Kaplan-Meier curves and compared using the logrank test. The results are presented as hazard ratios (HRs) with 95\% confidence intervals (CIs). Interactions between variables were evaluated. All statistical tests were two-tailed, and the significance level was set at $\mathrm{p}<0.05$. Statistical analyses were performed using the R program version 3.4.3 (The R Foundation 


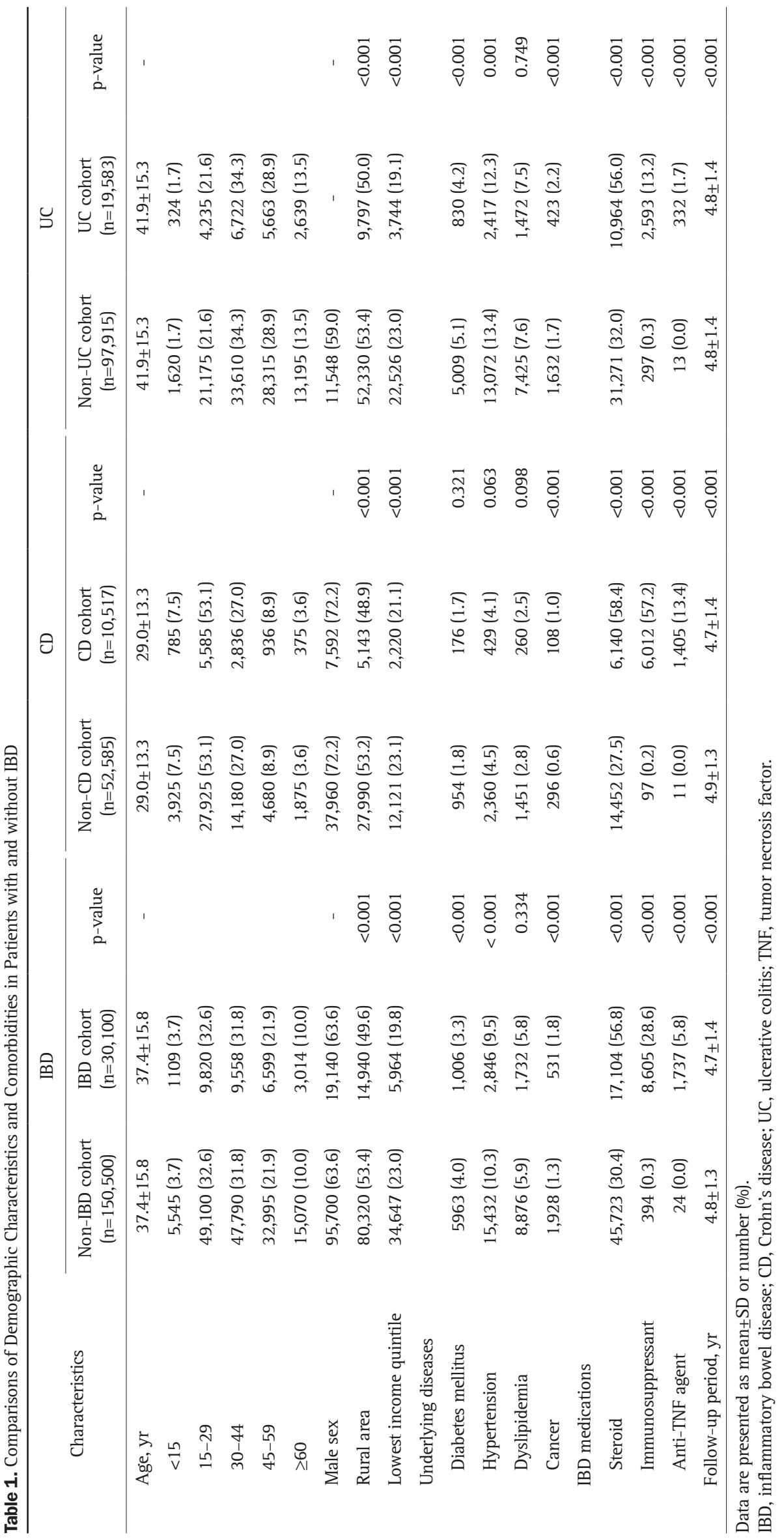


for Statistical Computing, Vienna, Austria) and SAS version 9.3 (SAS Institute Inc., Cary, NC, USA).

\section{Ethical considerations}

This study adhered to the tenets of the Declaration of Helsinki. As the database used in this study did not include personal identifiers and this study had a retrospective observational nature, informed consent was waived, and ethical approval was given by the Seoul National University Hospital Institutional Review Board (IRB number: H-1703-107-840).

\section{RESULTS}

\section{Baseline characteristics of the study population}

From 2010 to 2013, a total of 30,100 patients with IBD $(10,517$ CD and 19,583 UC) were included in the present study. In the $\mathrm{CD}$ cohort, 7,592 patients (72.2\%) were male, and the mean age was $29.0 \pm 13.3$ years old. In the UC cohort, 11,548 patients (59.0\%) were male, and the mean age was $41.9 \pm 15.3$ years old. As the controls for the CD and UC cohorts, 52,585 and 97,915 non-IBD individuals, respectively, matched by age and sex were included in this study. The baseline characteristics of both groups are summarized in Table 1. Compared with the non-IBD controls, the age- and sex-matched patients with IBD included significantly lower proportions of residents in rural areas $(p<0.001)$, those in the lowest income quintile $(p<0.001)$, and individuals with cancer $(\mathrm{p}<0.001)$. In addition, patients with UC (but not those with CD) had significantly lower prevalences of DM $(\mathrm{p}<0.001)$ and hypertension $(\mathrm{p}<0.001)$ than were found in the age- and sex-matched controls.

\section{Incidence of herpes zoster}

During a mean follow-up of 5.0 years, 2,071 patients (6.9\%) in the IBD group and 6,672 individuals (4.4\%) in the control group developed HZ. The incidence rates for HZ (per 1,000 person-years) were 14.51 and 9.19 in the IBD and control group, respectively, with an adjusted HR of 1.58 (95\% CI, 1.50 to $1.66 ; \mathrm{p}<0.001)$. Among IBD patients, the incidence rates for $\mathrm{HZ}$ (per 1,000 person-years) were 13.60 and 14.99 in the $\mathrm{CD}$ and UC groups, respectively. Compared to the controls, CD and UC patients had a significantly higher risk of HZ after multivariate adjustment for age, sex, and income (for CD patients: adjusted HR, 2.13; 95\% CI, 1.95 to 2.33; $\mathrm{p}<0.001$; and for UC patients: adjusted HR, 1.40; 95\% CI, 1.32 to 1.48 ; $\mathrm{p}<0.001$ ) (Table 2). The cumulative incidences of $\mathrm{HZ}$ in both the $\mathrm{CD}$ and UC patient groups were significantly higher than those found in the controls (log-rank test $\mathrm{p}<0.001$ ) (Fig. 1). The cumulative incidences of $\mathrm{HZ}$ in patients with $\mathrm{CD}$ were $1.4 \%, 4.0 \%$, and $6.7 \%$ at 1,3 , and 5 years, respectively. The cumulative incidences of $\mathrm{HZ}$ in patients with UC were $1.4 \%, 4.4 \%$, and $7.2 \%$ at 1,3 , and 5 years, respectively.

Table 2. Incidence and Adjusted HR of Herpes Zoster in IBD Patients versus Non-IBD Controls

\begin{tabular}{|c|c|c|c|c|c|}
\hline & HZ event & $\begin{array}{c}\text { HZ incidence } \\
\text { (per } 1,000 \text { person-years) }\end{array}$ & $\begin{array}{l}\text { Crude HR } \\
\text { (95\% CI) }\end{array}$ & $\begin{array}{c}\text { Adjusted HR } \\
(95 \% \mathrm{CI})^{*}\end{array}$ & p-value \\
\hline Total IBD & & & & & $<0.001$ \\
\hline Non-IBD cohort $(n=150,500)$ & 6,672 & 9.19 & 1 (reference) & 1 (reference) & \\
\hline Total IBD cohort $(n=30,100)$ & 2,071 & 14.51 & $1.58(1.50-1.66)$ & $1.58(1.50-1.66)$ & \\
\hline Subgroup analysis & & & & & $<0.001$ \\
\hline Incident IBD group $(\mathrm{n}=12,800)$ & 688 & 13.80 & $1.53(1.41-1.65)$ & $1.68(1.55-1.81)$ & \\
\hline Prevalent IBD group $(n=17,300)$ & 1,383 & 14.88 & $1.61(1.52-1.70)$ & $1.53(1.44-1.62)$ & \\
\hline $\mathrm{CD}$ & & & & & $<0.001$ \\
\hline Non-CD cohort $(n=52,585)$ & 1,645 & 6.44 & 1 (reference) & 1 (reference) & \\
\hline Total CD cohort $(n=10,517)$ & 676 & 13.60 & $2.11(1.93-2.31)$ & $2.13(1.95-2.33)$ & \\
\hline Subgroup analysis & & & & & $<0.001$ \\
\hline Incident $\mathrm{CD}$ group $(\mathrm{n}=4,614)$ & 227 & 12.80 & $2.02(1.76-2.32)$ & $2.21(1.92-2.54)$ & \\
\hline Prevalent CD group $(n=5,903)$ & 449 & 14.04 & $2.17(1.95-2.40)$ & $2.09(1.88-2.32)$ & \\
\hline UC & & & & & $<0.001$ \\
\hline Non-UC cohort $(n=97,915)$ & 5,027 & 10.69 & 1 (reference) & 1 (reference) & \\
\hline Total UC cohort $(n=19,583)$ & 1,395 & 14.99 & $1.40(1.32-1.49)$ & $1.40(1.32-1.48)$ & \\
\hline Subgroup analysis & & & & & $<0.001$ \\
\hline Incident UC group $(\mathrm{n}=8,186)$ & 461 & 14.36 & $1.37(1.24-1.51)$ & $1.50(1.36-1.65)$ & \\
\hline Prevalent UC group $(n=11,397)$ & 934 & 15.33 & $1.42(1.33-1.53)$ & $1.35(1.26-1.45)$ & \\
\hline
\end{tabular}

HR, hazard ratio; IBD, inflammatory bowel disease; HZ, herpes zoster; CI, confidence interval; CD, Crohn's disease; UC, ulcerative colitis. *Multiple analysis including age, sex, and income. 
A

Herpes zoster and CD

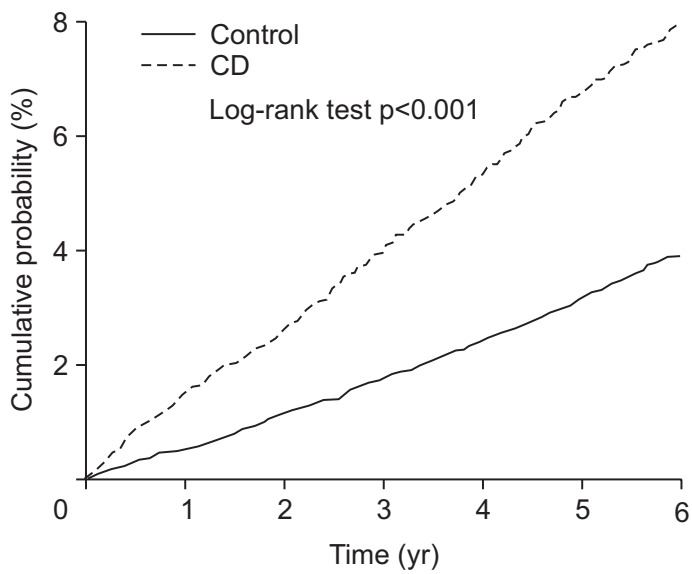

\begin{tabular}{|c|ccccccr|}
\hline \multicolumn{1}{|l|}{ No. at risk } & \multicolumn{6}{c|}{ Years after follow-up } \\
\hline & 0 & 1 & 2 & 3 & 4 & 5 & 6 \\
\cline { 2 - 8 } Control & 97,915 & 96,631 & 95,265 & 82,695 & 69,910 & 55,118 & 261 \\
CD & 19,583 & 19,231 & 18,845 & 16,337 & 13,763 & 10,837 & 46 \\
\hline
\end{tabular}

B

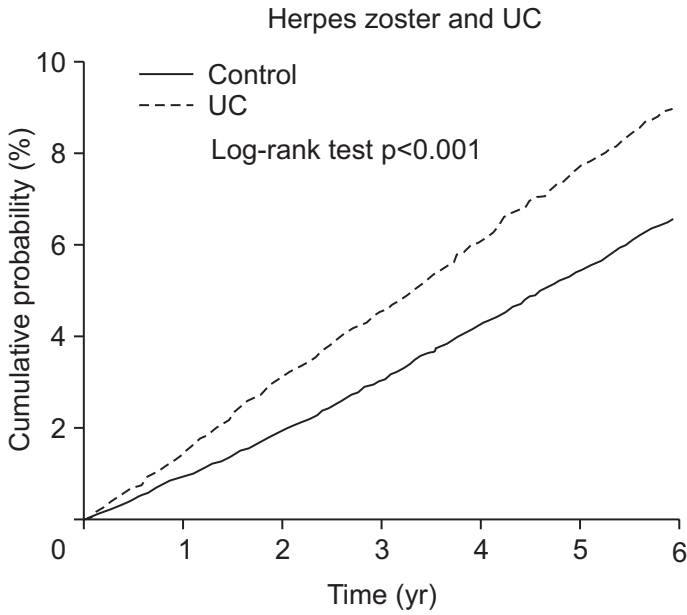

\begin{tabular}{|c|rrrrrrr|}
\hline \multicolumn{1}{|l|}{ No. at risk } & \multicolumn{7}{|c|}{ Years after follow-up } \\
\hline & 0 & 1 & 2 & \multicolumn{1}{c|}{3} & \multicolumn{1}{c|}{4} & \multicolumn{1}{c|}{5} & 6 \\
\cline { 2 - 8 } Control & 52,585 & 52,237 & 51,827 & 44,957 & 37,840 & 30,505 & 354 \\
UC & 10,517 & 10,306 & 10,148 & 8,718 & 7,258 & 5,808 & 62 \\
\hline
\end{tabular}

Fig. 1. Cumulative incidence comparison of ulcerative colitis in patients with inflammatory bowel disease. Cumulative incidence comparison of herpes zoster between patients (A) with Crohn's disease (CD) and (B) with ulcerative colitis (UC).

Table 3. Subgroup Analysis of the Impact of Crohn's Disease and Ulcerative Colitis on Herpes Zoster

\begin{tabular}{|c|c|c|c|c|}
\hline & \multicolumn{2}{|c|}{ Crohn's disease } & \multicolumn{2}{|c|}{ Ulcerative colitis } \\
\hline & $\begin{array}{l}\text { Adjusted HR } \\
(95 \% \mathrm{CI})^{*}\end{array}$ & $\begin{array}{l}\text { Interaction } \\
\text { p-value }\end{array}$ & $\begin{array}{l}\text { Adjusted HR } \\
(95 \% \mathrm{CI})^{*}\end{array}$ & $\begin{array}{c}\text { Interaction } \\
\text { p-value }\end{array}$ \\
\hline Age, yr & & 0.001 & & 0.014 \\
\hline$<15$ & $2.61(1.74-3.93)$ & & $2.51(1.13-5.59)$ & \\
\hline $15-29$ & $2.53(2.20-2.92)$ & & $1.70(1.44-2.02)$ & \\
\hline $30-44$ & $2.16(1.83-2.55)$ & & $1.37(1.22-1.55)$ & \\
\hline $45-59$ & $1.62(1.30-2.02)$ & & $1.44(1.31-1.58)$ & \\
\hline$\geq 60$ & $1.39(1.00-1.93)$ & & $1.22(1.08-1.39)$ & \\
\hline Sex & & 0.176 & & 0.002 \\
\hline Male & $2.23(2.00-2.49)$ & & $1.53(1.41-1.66)$ & \\
\hline Female & $1.96(1.68-2.28)$ & & $1.27(1.16-1.38)$ & \\
\hline Metabolic comorbidities $^{\dagger}$ & & 0.015 & & $<0.001$ \\
\hline No & $2.24(2.03-2.46)$ & & $1.49(1.39-1.60)$ & \\
\hline Yes & $1.59(1.23-2.06)$ & & $1.16(1.03-1.31)$ & \\
\hline Cancer & & 0.386 & & 0.181 \\
\hline No & $2.14(1.96-2.35)$ & & $1.41(1.33-1.50)$ & \\
\hline Yes & $1.46(0.63-3.39)$ & & $1.11(0.80-1.56)$ & \\
\hline
\end{tabular}

HR, hazard ratio; CI, confidence interval.

${ }^{*}$ Multiple analysis including age, sex, and income; ${ }^{\dagger}$ Presence of hypertension, diabetes mellitus, or dyslipidemia.

\section{Subgroup analysis}

The results of an interaction analysis of age, sex, metabolic comorbidities, and cancer are shown in Table 3. The impact of UC on the development of HZ was significantly more pro- nounced in male patients with UC (adjusted HR, 1.53; 95\% CI, 1.41 to 1.66 ) than in female patients with UC (adjusted HR, 1.27 ; $95 \%$ CI, 1.16 to 1.38 ; interaction $p=0.002$ ), but this relationship was not present in the $\mathrm{CD}$ group. All age subgroups in both the CD and UC patient groups had higher risks of HZ than 
were found int he controls, but the risk of $\mathrm{HZ}$ was significantly higher in younger patients (interaction $p=0.001$ and $p=0.014$ in CD and UC, respectively) (Fig. 2). Furthermore, the impact of CD was significantly more enhanced in patients without metabolic comorbidities (adjusted HR, 2.24; 95\% CI, 2.03 to 2.46) than in those with metabolic comorbidities (adjusted HR, 1.59; 95\% CI, 1.23 to 2.06; interaction $\mathrm{p}=0.015$ ). The impact of UC was also significantly higher in patients without metabolic comorbidities (adjusted HR, 1.49; 95\% CI, 1.39 to 1.60) than in those with metabolic comorbidities (adjusted HR, 1.16; 95\% CI, 1.03 to 1.31; interaction $\mathrm{p}<0.001)$.

In terms of medication for IBD, the results showed that steroids, immunomodulators, and anti-TNF agents significantly increased the risk of HZ in patients with CD and UC (all p-values <0.001) (Table 4). In patients with $\mathrm{CD}$, the risk of $\mathrm{HZ}$ was increased 1.40-, 1.45 -, and 1.55-fold (95\% CI, 1.20 to $1.64,1.26$ to 1.71 , and 1.26 to 1.90 ) in patients who received steroids, immunomodulators, and anti-TNF agents, respectively. In patients with UC, the risk of HZ was 1.43-, 1.35-, and 2.09-fold higher (95\% CI, 1.28 to
$1.60,1.17$ to 1.56 , and 1.47 to 2.97 ) in patients who received steroids, immunomodulators, and anti-TNF agents, respectively.

\section{DISCUSSION}

Our study has several strengths related to its study design and the claims data. First, it included all patients who were newly diagnosed with IBD in Korea from 2010 to 2013, thus minimizing selection bias. Second, the medication records were comprehensive and accurate, and results did not rely on patient recollection or medical records because the nationwide database provides complete data on all billed in- and outpatient prescriptions. In this nationwide population-based study, in which claims data from the NHI service were used, patients with IBD had a significantly higher risk of HZ than was found in the general population. Patients with IBD are vulnerable to HZ not only due to the innate immune dysregulations associated with chronic intestinal inflammation but also because of the use of immunosuppressive agents for the treatment of IBD. ${ }^{15,16}$ Hence,
A

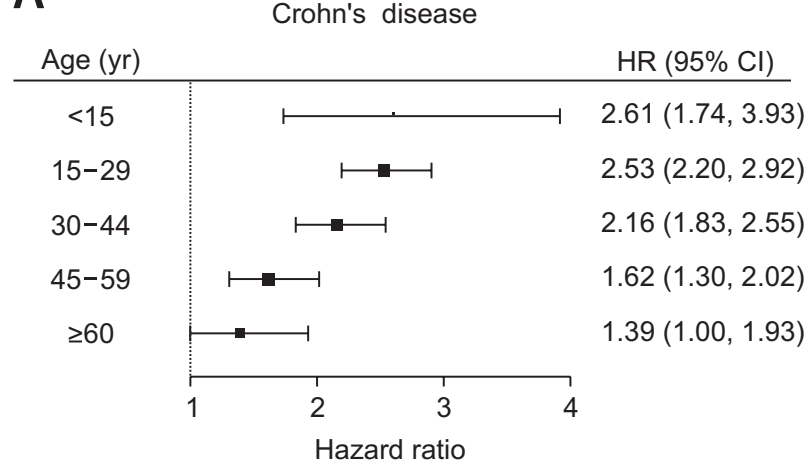

B

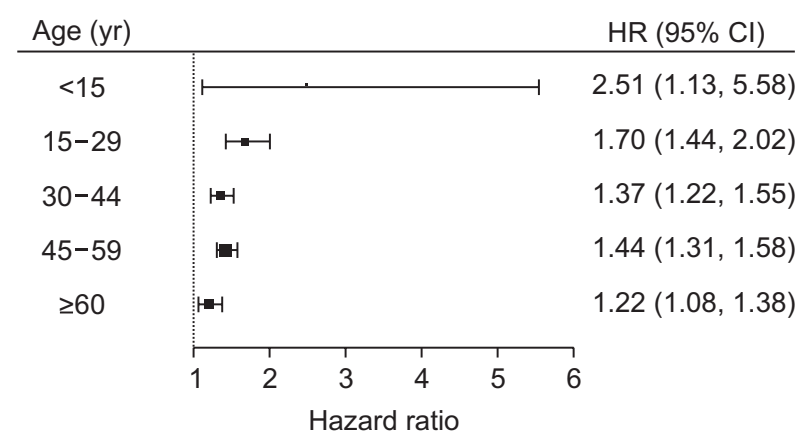

Fig. 2. Subgroup analysis of the impact of Crohn's disease (A) and ulcerative colitis on herpes zoster (B). $\mathrm{HR}$, hazard ratio; CI, confidence interval.

Table 4. Risk of Herpes Zoster According to Medication Use in Patients with Crohn's Disease and Ulcerative Colitis

\begin{tabular}{|c|c|c|c|c|c|c|c|c|}
\hline & \multicolumn{4}{|c|}{ Crohn's disease } & \multicolumn{4}{|c|}{ Ulcerative colitis } \\
\hline & $\begin{array}{c}\mathrm{HZ} \\
\text { event }\end{array}$ & $\begin{array}{l}\text { HZ incidence } \\
\text { (per } 1,000 \\
\text { person-years) }\end{array}$ & $\begin{array}{c}\text { Adjusted HR } \\
(95 \% \mathrm{CI})^{*}\end{array}$ & $\mathrm{p}$-value & $\begin{array}{c}\mathrm{HZ} \\
\text { event }\end{array}$ & $\begin{array}{l}\text { HZ incidence } \\
\text { (per } 1,000 \\
\text { person-years) }\end{array}$ & $\begin{array}{c}\text { Adjusted HR } \\
(95 \% \mathrm{CI})^{*}\end{array}$ & p-value \\
\hline Steroids & & & & $<0.001$ & & & & $<0.001$ \\
\hline No & 4,377 & 11.32 & 1 (reference) & & 8,619 & 12.068 & 1 (reference) & \\
\hline Yes & 6,140 & 15.39 & $1.40(1.20-1.64)$ & & 10,964 & 17.4096 & $1.43(1.28-1.60)$ & \\
\hline Immunomodulators & & & & $<0.001$ & & & & $<0.001$ \\
\hline No & 4,505 & 12.39 & 1 (reference) & & 16,990 & 14.574 & 1 (reference) & \\
\hline Yes & 6,012 & 14.52 & $1.45(1.26-1.71)$ & & 2,593 & 17.7299 & $1.35(1.17-1.56)$ & \\
\hline Anti-TNF agents & & & & $<0.001$ & & & & $<0.001$ \\
\hline No & 9,112 & 13.02 & 1 (reference) & & 19,251 & 14.8599 & 1 (reference) & \\
\hline Yes & 1,405 & 17.46 & $1.55(1.26-1.90)$ & & 332 & 24.2333 & 2.09 (1.47-2.97) & \\
\hline
\end{tabular}

HZ, herpes zoster; HR, hazard ratio; CI, confidence interval; TNF, tumor necrosis factor.

*Multiple analysis including age, sex, residence, income, hypertension, diabetes mellitus, dyslipidemia. 
understanding the epidemiology of HZ and identifying groups at high risk of $\mathrm{HZ}$ are both essential for physicians to predict and monitor the presentation of comorbid $\mathrm{HZ}$ in patients with IBD.

Several population-based studies have reported an increased risk of $\mathrm{HZ}$ in IBD. A nationwide population-based study performed in Taiwan reported a significantly increased risk for $\mathrm{HZ}$ in patients with $\mathrm{CD}$ and UC. ${ }^{17}$ Furthermore, a retrospective cohort study and retrospective nested case-control study conducted in the United Kingdom found an increased risk of $\mathrm{HZ}$ in IBD patients, with increased relative risks of 1.61 for $\mathrm{CD}$ patients and 1.21 for UC patients. That study revealed that $\mathrm{CD}$ patients had a significantly higher risk of $\mathrm{HZ}$ than was found in UC patients. ${ }^{11}$ Finally, a retrospective cohort study performed in the United States showed that the risk of $\mathrm{HZ}$ was higher in patients with IBD than in controls and that the risk of $\mathrm{HZ}$ was higher in CD patients than in UC patients (814 per 100,000 person-years vs 670 per 100,000 person-years). ${ }^{18}$ Our study demonstrated that the risk of $\mathrm{HZ}$ is higher in both $\mathrm{CD}$ and UC patients than in non-IBD controls. The increased risk of HZ in IBD is related to the following multifactorial factors. First, IBD is associated with both cellular and humoral immune dysfunctions, which lead to susceptibility to viral infection and reactivation. Effector T cells, which normally show intrinsic plasticity and adaptability to the surrounding environment, are biologically "stiff" in patients with IBD. A general activation of the humoral immune response with various alterations in immunoglobulin subclass production was detected in both CD and UC patients, and this may influence the host response to HZ. ${ }^{19-21}$ Second, the risk of HZ increases in patients with IBD because of the use of medications for IBD, which include steroids, immunomodulators, and anti-TNF agents, consistent with our results. Third, psychological stress and chronic fatigue may contribute to the immunocompromised state associated with the increased risk of $\mathrm{HZ}$ in patients with IBD. ${ }^{17}$ In addition, our study revealed that the adjusted HR of $\mathrm{HZ}$ was higher in patients with CD than in those with UC or nonIBD controls. These findings are consistent with the results of previous studies performed in Western countries. Patients with $\mathrm{CD}$ may have a higher risk of developing $\mathrm{HZ}$ than do those with UC, even though the analysis of non-IBD controls versus the UC group revealed more risk factors for $\mathrm{HZ}$ that were based on old age and the proportion of metabolic comorbidities and steroid use than were found in the comparison of the control group and the CD group in this study.

Considering the relationship between age and the risk of $\mathrm{HZ}$ in IBD, the results of this study show that younger patients with IBD are significantly more vulnerable than the general population to HZ. Although all age groups with IBD had a higher risk of $\mathrm{HZ}$ than was found in the controls, the risk of developing $\mathrm{HZ}$ was significantly more prominent in younger patients with IBD. Previous studies have highlighted the notion that there is an increased risk of $\mathrm{HZ}$ in younger patients with other comorbidities.
A retrospective study performed using claims data in the Unites States illustrated that the risk of $\mathrm{HZ}$ was higher in younger patients with systemic lupus erythematosus. ${ }^{22}$ A single-center retrospective study also showed that the risk of $\mathrm{HZ}$ was higher in younger patients who received liver transplantations, and this supports the need for vaccination among younger patients. ${ }^{23}$ A retrospective population-based study performed in Taiwan reported a high risk of $\mathrm{HZ}$ in patients with psoriasis who were aged between 20 and 39 years old. ${ }^{24}$ Taken together, these data indicate that younger patients with chronic inflammatory disorders that require systemic immunosuppressive therapy have a relatively higher risk than the general population of developing HZ. Therefore, even young patients with IBD should be made aware of their possible risk for developing HZ.

In terms of metabolic comorbidities, several previous studies have demonstrated that the risk of $\mathrm{HZ}$ is higher in patients with DM, hypertension, and dyslipidemia. The pathogenesis of $\mathrm{HZ}$ in patients with metabolic comorbidities can be explained by impaired cellular immunity. Decreased VZV-specific cell-mediated immunity specific to VZV was observed in patients with DM. ${ }^{8-10}$ In this study, however, we found that the risk of $\mathrm{HZ}$ was relatively higher in IBD patients without metabolic comorbidities. Indeed, such finding may indicate a confounding factor as younger patients have been found to have an increased risk of $\mathrm{HZ}$. However, a subgroup analysis performed after individuals were divided into two groups, patients younger than or equal to/older than 30 years old, also showed that in each age group, patients without comorbidities had a higher risk than the general population of developing both CD and UC (Supplementary Table 1). Hence, it is sufficient to conclude that being metabolically healthy independently increases the risk of HZ. Considering the potential risk of $\mathrm{HZ}$ in variable chronic inflammatory disorders, including psoriasis, rheumatoid arthritis, and chronic obstructive pulmonary disease, ${ }^{22,24-26}$ in patients with IBD who are metabolically healthy, the presence of IBD itself may raise the risk of HZ compared to the general population.

Additionally, our study reveals that the risk of $\mathrm{HZ}$ is increased in patients with IBD who were treated with steroids, immunomodulators, or anti-TNF agents. This finding is consistent with the results of previous reports performed in patients with IBD. A retrospective cohort study performed using administrative data obtained in the Unites States showed that IBD medications, including steroids, thiopurines, and anti-TNF agents, were independently associated with an increased risk of $\mathrm{HZ} .{ }^{18}$ A retrospective cohort study performed using the national administrative database from the United States Department of Veterans Affairs also illustrated that medication use, such as glucocorticoids, methotrexate, azathioprine, cyclosporine, and anti-TNF agents, increased the risk of $\mathrm{HZ}{ }^{27}$ These medications, which are used for the treatment of IBD, contribute to the presentation of $\mathrm{HZ}$ via various pathways. Glucocorticoids are potent immunosuppressive drugs that induce lymphopenia, resulting in a 
superimposed risk of $\mathrm{HZ}$ in patients with systemic inflammatory diseases. ${ }^{28}$ Immunomodulators have been shown to increase the risk of $\mathrm{HZ}$ in several studies involving patients with rheumatoid arthritis. ${ }^{25,27}$ Lastly, there is some debate concerning the effect of anti-TNF agents on the development of HZ. Some previous studies have shown that treatment with anti-TNF agents was not associated with an increased risk of $\mathrm{HZ},{ }^{15}$ while others have reported an increased risk of $\mathrm{HZ}$ in patients with anti-TNF treatment, suggesting that TNF plays a critical role in the control of viral infection. ${ }^{25,29-32} \mathrm{TNF}-\alpha$ is produced by macrophages and Tlymphocytes and induces the differentiation of monocytes into macrophages, neutrophil recruitment, and granuloma formation. $^{33-35}$ The molecular effects of TNF- $\alpha$ are essential to cellmediated immune responses and the defense mechanisms activated in response to viral infection.

Recently, a nationwide population-based study showing that the risk of HZ was higher in Korean IBD using claims data obtained from the Health Insurance Review and Assessment (HIRA) service, which reviews health insurance claims in Korea. ${ }^{36}$ Compared to the NHI, the HIRA databases offer a maximum of 5 years of data due to the limited storage period of the claims data. ${ }^{37}$ Thus, the washout period is insufficient in that it may not completely remove all prevalent cases from the incident case group for IBD. In addition, some information related to demographics, such as income and resident area, is not available from the HIRA database, and the results of an analysis of crude standardized incidence ratios of $\mathrm{HZ}$ obtained from a previous study were not adjusted for underlying comorbidities, including metabolic diseases and cancers, and concurrent medication for IBD, which are well-known risk factors for HZ infection. Our findings are highly valuable because they should that the risks associated with HZ in patients with IBD are significant even after all considerable risk factors were adjusted.

This study has several limitations. First, the database available from the NHI does not provide information on serum laboratory results or endoscopic findings and therefore allows only a limited evaluation of IBD disease activity. Because the database also does not provide information on some possible confounding variables, such as alcohol consumption, body mass index, physical activity, or family history of systemic diseases, these variables could not be adjusted for to better calculate the risk of HZ in this study population. Second, information on vaccinations for VZV is not available in the NHI database. Thus, the impact of vaccination for VZV on the development of $\mathrm{HZ}$ could not be evaluated. Previous studies have shown that the VZV vaccination is effective in reducing the incidence of $\mathrm{HZ}$ and postherpetic neuralgia in adults older than 60 years old. ${ }^{3,38-40}$ Further prospective studies are needed to determine whether vaccination for VZV prevents the development of HZ in IBD, especially in younger patients without any metabolic comorbidities.

In conclusion, the risk of $\mathrm{HZ}$ is higher in patients with IBD than in the general population. Therefore, even young patients without any metabolic comorbidities should be carefully monitored for the development of HZ if they are taking immunosuppressive therapy for IBD.

\section{CONFLICTS OF INTEREST}

No potential conflict of interest relevant to this article was reported.

\section{ACKNOWLEDGEMENTS}

Author contributions: Study concept and design: H.S., K.H. Acquisition of patient data: H.S., S.P., G.C., K.H., J.K., J.L. Analysis and interpretation of data: H.S., K.H., J.C. Drafting of the manuscript: H.S., J.C. Critical revision of the manuscript for important intellectual content: H.S., S.P., G.C., J.H., J.K., J.L., J.C., J.P.I., J.S.K. Statistical analysis: K.H. Study supervision: J.C., J.P.I., J.S.K. All authors reviewed and approved the final manuscript.

\section{REFERENCES}

1. Mahalingam R, Wellish M, Wolf W, et al. Latent varicella-zoster viral DNA in human trigeminal and thoracic ganglia. $\mathrm{N}$ Engl $\mathrm{J}$ Med 1990;323:627-631.

2. Cullen G, Baden RP, Cheifetz AS. Varicella zoster virus infection in inflammatory bowel disease. Inflamm Bowel Dis 2012;18:23922403.

3. Oxman MN, Levin MJ, Johnson GR, et al. A vaccine to prevent herpes zoster and postherpetic neuralgia in older adults. $\mathrm{N}$ Engl $\mathrm{J}$ Med 2005;352:2271-2284.

4. Yawn BP, Saddier P, Wollan PC, St Sauver JL, Kurland MJ, Sy LS. A population-based study of the incidence and complication rates of herpes zoster before zoster vaccine introduction. Mayo Clin Proc 2007;82:1341-1349.

5. Lin YH, Huang LM, Chang IS, et al. Disease burden and epidemiology of herpes zoster in pre-vaccine Taiwan. Vaccine 2010;28:12171220.

6. Kim YJ, Lee CN, Lim CY, Jeon WS, Park YM. Population-based study of the epidemiology of herpes zoster in Korea. J Korean Med Sci 2014;29:1706-1710.

7. Arvin A. Aging, immunity, and the varicella-zoster virus. N Engl J Med 2005;352:2266-2267.

8. Kawai K, Yawn BP. Risk factors for herpes zoster: a systematic review and meta-analysis. Mayo Clin Proc 2017;92:1806-1821.

9. Joesoef RM, Harpaz R, Leung J, Bialek SR. Chronic medical conditions as risk factors for herpes zoster. Mayo Clin Proc 2012;87:961-967.

10. Esteban-Vasallo MD, Domínguez-Berjón MF, Gil-Prieto R, AstrayMochales J, Gil de Miguel A. Sociodemographic characteristics and chronic medical conditions as risk factors for herpes zoster: a population-based study from primary care in Madrid (Spain). Hum 
Vaccin Immunother 2014;10:1650-1660.

11. Gupta G, Lautenbach E, Lewis JD. Incidence and risk factors for herpes zoster among patients with inflammatory bowel disease. Clin Gastroenterol Hepatol 2006;4:1483-1490.

12. Marehbian J, Arrighi HM, Hass S, Tian H, Sandborn WJ. Adverse events associated with common therapy regimens for moderateto-severe Crohn's disease. Am J Gastroenterol 2009;104:25242533.

13. Jung YS, Han M, Park S, Kim WH, Cheon JH. Cancer risk in the early stages of inflammatory bowel disease in Korean patients: a nationwide population-based study. J Crohns Colitis 2017;11:954962.

14. Ahn IM, Park DH, Hann HJ, Kim KH, Kim HJ, Ahn HS. Incidence, prevalence, and survival of moyamoya disease in Korea: a nationwide, population-based study. Stroke 2014;45:1090-1095.

15. Khan N, Trivedi C, Shah Y, Patel D, Lewis J, Yang YX. The severity of herpes zoster in inflammatory bowel disease patients treated with anti-TNF agents. Inflamm Bowel Dis 2018;24:1274-1279.

16. Côté-Daigneault J, Peerani F, MacMahon E, Delaporte E, Rahier $\mathrm{JF}$, Colombel JF. Management and prevention of herpes zoster in the immunocompromised inflammatory bowel disease patient: a clinical quandary. Inflamm Bowel Dis 2016;22:2538-2547.

17. Tsai SY, Yang TY, Lin CL, Tsai YH, Kuo CF, Kao CH. Increased risk of varicella zoster virus infection in inflammatory bowel disease in an Asian population: a nationwide population-based cohort study. Int J Clin Pract 2015;69:228-234.

18. Long MD, Martin C, Sandler RS, Kappelman MD. Increased risk of herpes zoster among 108604 patients with inflammatory bowel disease. Aliment Pharmacol Ther 2013;37:420-429.

19. de Souza HS, Fiocchi C. Immunopathogenesis of IBD: current state of the art. Nat Rev Gastroenterol Hepatol 2016;13:13-27.

20. Murphy KM, Stockinger B. Effector T cell plasticity: flexibility in the face of changing circumstances. Nat Immunol 2010;11:674680.

21. Scott MG, Nahm MH, Macke K, Nash GS, Bertovich MJ, MacDermott RP. Spontaneous secretion of IgG subclasses by intestinal mononuclear cells: differences between ulcerative colitis, Crohn's disease, and controls. Clin Exp Immunol 1986;66:209-215.

22. Yun H, Yang S, Chen L, et al. Risk of herpes zoster in autoimmune and inflammatory diseases: implications for vaccination. Arthritis Rheumatol 2016;68:2328-2337.

23. Herrero JI, Quiroga J, Sangro B, et al. Herpes zoster after liver transplantation: incidence, risk factors, and complications. Liver Transpl 2004;10:1140-1143.

24. Tsai SY, Chen HJ, Lio CF, et al. Increased risk of herpes zoster in patients with psoriasis: a population-based retrospective cohort study. PLoS One 2017 22;12:e0179447.

25. Strangfeld A, Listing J, Herzer P, et al. Risk of herpes zoster in patients with rheumatoid arthritis treated with anti-TNF-alpha agents. JAMA 2009;301:737-744.
26. Yang YW, Chen YH, Wang KH, Wang CY, Lin HW. Risk of herpes zoster among patients with chronic obstructive pulmonary disease: a population-based study. CMAJ 2011;183:E275-E280.

27. McDonald JR, Zeringue AL, Caplan L, et al. Herpes zoster risk factors in a national cohort of veterans with rheumatoid arthritis. Clin Infect Dis 2009;48:1364-1371.

28. Hu SC, Lin CL, Lu YW, et al. Lymphopaenia, anti-Ro/anti-RNP autoantibodies, renal involvement and cyclophosphamide use correlate with increased risk of herpes zoster in patients with systemic lupus erythematosus. Acta Derm Venereol 2013;93:314-318.

29. Kim SY, Solomon DH. Tumor necrosis factor blockade and the risk of viral infection. Nat Rev Rheumatol 2010;6:165-174.

30. Liao TL, Chen YM, Liu HJ, Chen DY. Risk and severity of herpes zoster in patients with rheumatoid arthritis receiving different immunosuppressive medications: a case-control study in Asia. BMJ Open 2017;7:e014032.

31. Katsanos KH, Papadakis KA. Inflammatory bowel disease: updates on molecular targets for biologics. Gut Liver 2017;11:455-463.

32. Algood HM, Lin PL, Flynn JL. Tumor necrosis factor and chemokine interactions in the formation and maintenance of granulomas in tuberculosis. Clin Infect Dis 2005;41 Suppl 3:S189-S193.

33. Kindler V, Sappino AP, Grau GE, Piguet PF, Vassalli P. The inducing role of tumor necrosis factor in the development of bactericidal granulomas during BCG infection. Cell 1989;56:731-740.

34. Park DI, Hisamatsu T, Chen M, et al. Asian Organization for Crohn's and Colitis and Asia Pacific Association of Gastroenterology consensus on tuberculosis infection in patients with inflammatory bowel disease receiving anti-tumor necrosis factor treatment. Part 1: risk assessment. Intest Res 2018;16:4-16.

35. Lee JW, Choi CH, Park JH, et al. Clinical features of active tuberculosis that developed during anti-tumor necrosis factor therapy in patients with inflammatory bowel disease. Intest Res 2016;14:146151.

36. Chang K, Lee HS, Kim YJ, et al. Increased risk of herpes zoster infection in patients with inflammatory bowel diseases in Korea. Clin Gastroenterol Hepatol 2018;16:1928-1936.e2.

37. Kim JA, Yoon S, Kim LY, Kim DS. Towards actualizing the value potential of Korea Health Insurance Review and Assessment (HIRA) data as a resource for health research: strengths, limitations, applications, and strategies for optimal use of HIRA data. J Korean Med Sci 2017;32:718-728.

38. Levin MJ, Oxman MN, Zhang JH, et al. Varicella-zoster virusspecific immune responses in elderly recipients of a herpes zoster vaccine. J Infect Dis 2008;197:825-835.

39. Mills R, Tyring SK, Levin MJ, et al. Safety, tolerability, and immunogenicity of zoster vaccine in subjects with a history of herpes zoster. Vaccine 2010;28:4204-4209.

40. Jung YS, Park JH, Kim HJ, et al. Insufficient knowledge of Korean gastroenterologists regarding the vaccination of patients with inflammatory bowel disease. Gut Liver 2014;8:242-247. 